\title{
Tradução e o Contexto Cultural: Será que o dicionário basta?
}

\author{
Nancy Rozenchan
}

\begin{abstract}
Resumo: A quantidade de fatores que interfere na tradução a partir do hebraico é mais ampla do que a da maior parte das línguas contemporâneas. Além das várias camadas históricas que compõem a língua, a fartura e a diversidade de elementos culturais imbricados atualmente na linguagem coloquial apontam para a dificuldade do tradutor cumprir os seus propósitos baseando-se somente em dicionários. Através de exemplos, são indicados alguns destes elementos culturais.
\end{abstract}

Palavras-chave: língua hebraica; tradução; tradução e cultura.

Segundo a destacada escritora israelense Shulamit Hareven, a boa notícia sobre escrever em uma língua tão antiga quanto o hebraico é que, ao menos em teoria, "a pessoa pode mergulhar em qualquer camada lingüística para tornar o sentido ou nuance do seu texto mais precisos." Há uma imensa riqueza de possibilidades que vai de uma linguagem bíblica carregada de espiritualidade, até o estilo legalista da mishná, a codificação da lei oral.

A má notícia é que esta riqueza é que é capaz de tornar o bom hebraico praticamente intraduzível. Porém Hareven ainda acrescenta: "Muito se perde na tradução, mas mais ainda se perde quando um autor não é traduzido." Para que escritores hebraicos possam ser lidos por grandes públicos, eles devem ser traduzidos e, se possível, transplantados para outras línguas e culturas com o cuidado de transmitir características do original.

Se procuramos esclarecer tal situação, vemos que fatores que devem ser levados em consideração por quem traduz e por quem precisa ou pretende usufruir de uma tradução são bem mais complexos, particularmente quando se deve levar em conta o larguíssimo contexto cultural israelense. Como pretendemos abordar a lin- 
guagem contemporânea e do dia-a-dia, não é apenas a camadas de antigüidade que servem principalmente a norma culta a que devemos nos ater. Uma rápida reflexão a respeito da língua usada atualmente pode esclarecer o seu contexto e expressão.

Um dos mais populares comentaristas da língua hebraica, Ruvik Rosenthal, refere-se à língua trivial denominando-a de hebraico israelense, uma forma de expressão intrinsecamente vinculada ao próprio caráter de israelidade, uma linguagem cuja função é de ligação entre os diversos setores do país ante a confusão na compreensão na passagem da linguagem de um setor para a linguagem central.

$\mathrm{O}$ hebraico israelense reflete a israelidade e também cumpre nela um papel. O hebraico reflete a israelidade porque, como ela, é um processo dinâmico que não foi completado, um pouco caótico, colorido, profundo e raso ao mesmo tempo. Para definir a linguagem israelense, é preciso discernir entre a "linguagem central" e diversas linguagens setoriais (comunidades religiosas, de acontecimentos sociais, acadêmicos, high-tech, internet, chat, influência da intifada na linguagem do exército, universo das drogas, e assim por diante). A linguagem central é a que todos entendem, ou que todos usam no espaço público comum. O agente central desta língua é a mídia, ou seja, jornais, diários, redes de rádio e de televisão. O hebraico israelense não é a linguagem central e nem uma substituta, mas o conjunto todo, o sistema de relações, e quanto uma linguagem alimenta a outra. Ela é definida em termos de processo ou de acontecimento e não de um código lingüístico demarcado.

O hebraico vivo está se achatando, desgastando-se, perdendo as suas cargas culturais mais antigas. Há no hebraico israelense uma tendência crescente e que vai ficando mais forte de ignorar nuances ao mesmo tempo em que ocorre o predomínio de poucas palavras com muitos sentidos, uma crescente polissemia. Com isto, o hebraico israelense reflete a doença israelense de se voltar a um denominador comum baixo e raso, a uma crueza de pensamento e de comportamento que brota em muitos espaços da israelidade. Não se pense que escritores não têm parcela de responsabilidade neste processo. A escrita pós-moderna de Orly Castel-Bloom e de Etgar Kéret, por exemplo, ambos com algum material traduzido ao português, tem sido, no nível literário e, podemos dizer, de alto padrão, responsável por considerável reviravolta na língua culta. É verdade que, com isto, ao mesmo tempo, aproximaram muitos novos leitores da literatura. Como ambos estão vinculados ao universo do cinema, das histórias em quadrinhos e da televisão, parte do seu estilo e o enfoque da temática devem ser compreendidos levando em conta estes meios de comunicação com sua rapidez na veiculação e fragmentação da mensagem. Outro aspecto das alterações e deteriorações lingüísticas que chama a atenção é que isto

82 Nancy Rozenchan - Tradução e o contexto cultural: será que o dicionário basta? 
ocorre em ambientes sofisticados centrais e não apenas em periferias rarefeitas do ponto de vista cultural; freqüentemente fala-se, por exemplo, da linguagem "sheinkiniana", referência a uma das ruas mais sofisticadas de Tel Aviv e do país, a R. Sheinkin, um universo de peso com seus cafés e restaurantes fervilhantes.

Ainda que fenômenos semelhantes possam ser eventualmente observados em uma ou outra língua, a densidade e a concentração de fatores de interferência na moldagem do hebraico contemporâneo ultrapassam qualquer registro quantitativo ou qualificativo.

Uma língua é de forma simultânea indicadora tanto da realidade material e nãomaterial da cultura que lhe está tradicionalmente associada, simbólica daquela cultura e de pertença a ela e, por isto, como todos os símbolos, facilmente politizada e, finalmente, a língua é também parte e parcela da carga de qualquer cultura. Cultura e linguagem são, em grande parte, idênticas mais do que meramente co-ocorrências pelas quais são, com muita freqüência, tomadas.

Apreciações sobre a língua podem parecer dispensáveis quando se está falando de tradução, mas as particularidades do que ocorre com o hebraico indicam o contrário. Um conhecimento da situação atual da língua hebraica pode colaborar com quem se propõe a lidar com tradução e ajudar a resolver questões de que os dicionários não tratam.

Assim, considero igualmente importante trazer algumas concepções do lingüista Ghil'ad Zuckermann, da Universidade de Cambridge, a respeito do hebraico. Zuckermann, de forma e por motivos inusitados, chama aquilo que muitos normalmente denominam de "hebraico moderno", de "israelense", ou seja, língua israelense. Baseia-se para isto na interação entre lexis (vocabulário) e política, assunto que, segundo ele, é freqüentemente negligenciado pelos lingüistas teóricos. Zuckermann menciona o ponto de vista tradicional que sugere que a língua israelense é semítica: o hebraico bíblico e o mishnáico revividos. Uma posição revisionista de Zuckerman, baseada nos lingüistas Horvath (da Hungria) e Wexler (da Universidade de Tel Aviv), define a língua israelense como indo-européia: um ídiche relexificado, isto é, o ídiche, língua-mãe dos "revivificadores", é o substrato, enquanto o hebraico é apenas um superstrato. A hipótese de Zuckermann é que a língua israelense é simultaneamente tanto semítica como indo-européia; tanto o hebraico como o ídiche atuam como seus participantes primários, ao invés de serem substrato e superstrato. Por isto, ele considera que a denominação de "língua israelense" é muito mais apropriada do que "hebraico israelense", para não falar de "hebraico moderno". 
Aqui, para facilitar a compreensão, apesar das classificações mencionadas, farei menção apenas a "hebraico".

Posto isto, tentarei indicar através de uns poucos exemplos como e por que a abordagem cultural se faz absolutamente necessária e indispensável no ofício da tradução desta língua.

Se alguém pretender localizar no dicionário a expressão iefê hablorit, ficará desapontado. No máximo, após desmembrar a expressão, ficará com algo como "de belo topete", o que, na origem, não está errado mas que atualmente se perde caso não receba a devida tutoria cultural.

A expressão é da década de 40, do século passado, de um poema de Chaim Guri, "Hareut", (A amizade), musicado por Sacha Argov, cantado inicialmente por um conjunto musical da Palmach, a força de elite do exército não oficial existente antes que Israel se tornasse uma nação independente, o Tshizbatron e, depois por muitos outros intérpretes. A época da Palmach (final da década de 1940) é considerada um período glorioso da história de Israel, de pureza, despojamento, atuação em prol do benefício geral, com todos os sentidos e intenções voltados para a edificação do país que estava por surgir. O poema fala da fraternidade que uniu os que combatiam, todos movidos pelos mesmos ideais, e a lembrança dos mortos que não seriam esquecidos, os "belos heróis", iefê hablorit vehatoar.

Em fotos de então, vemos que estes rapazes idealistas, jovens, exibiam em geral belos topetes, provavelmente um elemento da moda. Pareciam-se nisto como se pareciam no caráter, no espírito de camaradagem.

Para a palavra "belo", de beleza física, temos, como opção, iefêe toar; para beleza de caráter, temos iefê néfesh. Foi Guri provavelmente que ampliou o termo e cunhou-o com a inclusão de blorit, o topete; e, se não foi ele, então ao menos Guri fez com que ele se perpetuasse simbolizando tudo o que de positivo e majestoso houve naquela geração e o contexto da amizade pois, como ele escreveu, uma amizade destas jamais poderá ser esquecida.

Não posso dizer que tenhamos uma tradução conveniente para o português; três versões diferentes do poema para o inglês, se pudessem se somar, resultariam em um bom trabalho final: beautiful of mind and body, youth and splendour $\mathrm{e}$ the ones of handsome forlock, so pure.

Com tudo isto, se precisamos hoje traduzir esta expressão, uma das diversas que são referência específica à criação do Estado de Israel, e a expressão continua sendo muito usada em variados contextos, talvez fosse necessário optar por algo que abrangesse a idéia de que um país se construiu graças à moral dos que deram a vida por ele.

84 Nancy Rozenchan - Tradução e o contexto cultural: será que o dicionário basta? 
Ao mesmo tempo, entretanto, não se pode ignorar que estes homens foram heróis tornados ídolos, típicos do machismo que foi a corrente central da época.

Este poema/música é associado no presente ao nome de Itz'hak Rabin e o que ele representou para a história de Israel, já que "Hareut" foi uma das suas músicas prediletas. Rabin também tinha sido um dos de "belo topete".

Há muitos casos em que a tradutibilidade de uma expressão deve passar por uma tutoria que abranja um conhecimento prévio do caráter de um povo, de seus sentimentos, de sua história de sua formação. O exemplo que trazemos do ídiche é tirado de um recém-lançado livro de bênçãos e maldições publicado pela Universidade Hebraica de Jerusalém, de autoria de Yossef Guri (é coincidência de nomes, mas não tem a ver com o poeta mencionado há pouco).

Por vários motivos trazemos um exemplo do ídiche, a saber:

Tradicionalmente o hebraico tem maldições muito drásticas como as que constam nas seções de repreensões da Bíblia (Levítico 26:14-45 e Deuteronômio 28:1568), com gradações cumulativas para o caso em que os preceitos divinos não são cumpridos. Parece-nos que, ante isto, no decorrer dos séculos, o hebraico, com o seu caráter de língua sagrada, não ousou ampliar este repertório, e os conhecedores da língua não podiam fazer algo além do que constava na Bíblia. Em tal elaboração destacaram-se as outras línguas faladas pelos judeus, em particular o ídiche, a língua de séculos de comunicação popular e também erudita dos judeus da Europa Central e Oriental. O hebraico falado, renascido no século XX, seja pelo caráter de sacralidade, seja pelo nível alto, culto, que pretendeu preservar, viu-se às voltas com uma precariedade neste campo. Valeu-se, então, do que os seus falantes trouxeram das outras línguas e culturas que dominavam: o árabe, o russo, o polonês, o judeu-espanhol, mas principalmente o ídiche. Esta forma de expressão foi muito desenvolvida no ídiche e é mais rica e variada que expressões similares existentes no folclore de muitos outros povos. As maldições do ídiche devem ser diferenciadas daquelas dos mencionados capítulos do Pentateuco, de Deus contra os infiéis; inserem-se na categoria de maldições coloquiais. As maldições coloquiais são mais expressões de irrupções passageiras de raiva, mesmo quando conseguem ser bastante veementes e maldosas e, segundo Yossef Guri, que parafraseia pesquisadores anteriores, uma palavra é apenas uma palavra e não é capaz de fazer mal.

Entre muitos povos, descarregar a tensão nervosa após uma experiência desagradável é feito pelo uso de uma linguagem abominável. Os judeus do leste europeu aliviavam as suas usando maldições e formas de praguejar que freqüentemente eram carregadas de humor, com vocabulário do uso diário. Mas houve muitas cal- 
cadas no hebraico bíblico e seu contexto cultural. Os falantes do ídiche estão acostumados a observações espirituosas e a chistes. No seu desenvolvimento no século XX, o hebraico não foi capaz de adotar caráter semelhante. Daí, por que, as expressões de bênção e maldição do ídiche ainda contam para o hebraico, pelo conteúdo, pela carga que transmitem e, em especial, pela forma. Como disse o escritor Aharon Mégued a respeito do ídiche: o ídiche tem certas propriedades que não são encontradas no hebraico: é uma língua mais "soft", mais quente que o hebraico que é "aristocrático" por causa de suas ligações com a bíblia e o Talmude. Ídiche é uma língua mais "folk". E, ainda, como escreveu há pouco o Prof. Guershon Shaked, referindo-se ao substrato ídiche da escrita hebraica do recém-falecido contista Yossl Birstein: "Esta é a língua sofisticada e cálida que contorna a aspereza e a irrefreabilidade tão característica da vida do país. Ela é temperada com um humor que mais perdoa do que escarnece, é mais compreensível do que crítica, e que tem um sorriso que não se sabe se é beneplácito ou de desespero, mas que expressa, principalmente, a prontidão de aceitar a vida tal como ela é."

Mais um motivo para que se traga aqui um modelo do ídiche, é que, muitas vezes, estas falas eram baseadas no vocabulário e cultura registrados em hebraico, mormente de origem bíblica, que proporcionam uma base riquíssima de conotações.

O exemplo a seguir é dos mais expressivos:

"Homens guedule um Koreches nes zoln dich trefn."

Ao pé da letra: "Que a grandeza de Amã e o milagre de Coré te atinjam!"

O que parece aí uma magnífica bênção (grandeza, milagre) é, na verdade, uma tremenda maldição disfarçada, com grande dose de ironia: a "grandeza" de Amã, o malvado ministro do livro de Éster, é a altura da forca onde ele morrerá, o "milagre" de Coré é a referência ao prestigioso primo de Moisés que contesta o papel que lhe cabe e que também aspirava a mais poder (Números 16:1 - 18:32) e que promove uma espécie de levante. Deus não aceita a provocação e promove um milagre, a terra se abre e engole Coré e companheiros. No caso destas duas figuras, elas são unidas pela punição/vingança que é base dos dois eventos. Um tradutor que não esteja devidamente preparado, poderá se deixar levar de forma enganosa em expressões desta categoria.

Minha inspiração para um outro exemplo de tradução que pode demandar algum apoio cultural surgiu de um programa popular de televisão brasileira em que artistas se manifestavam sobre inveja, motivados pelo que vem sendo a tônica de 

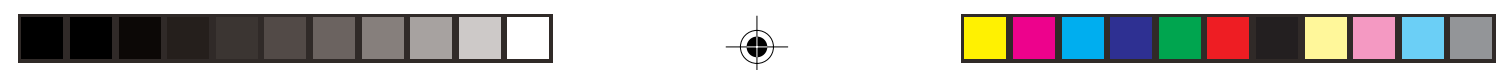

algumas das nossas novelas. Uma entrevistada, ao explicar que sente à vezes um tipo de inveja que, a seu ver, não é prejudicial, deu-me a tradução da palavra ídiche já dicionarizada em hebraico, "lefarguen". Dizia ela que existe inveja "boa" e inveja "má". A língua hebraica ressentia-se de uma tal expressão que a atriz brasileira chamou de "inveja boa". O hebraico, que somente possuía uma palavra para a "inveja má", adotou a forma ídiche "lefarguen" para a tal da inveja boa. O dicionário de ídiche usa como uma das traduções para este verbo "não invejar". Dos dicionários hebraicos, o de Mordechai Mishor e Shoshana Bahat aponta como tradução "relacionar-se sem inveja, sem estreiteza de sentimento"; o tradicional Even Shoshan vai na mesma linha; o Babylon também menciona "falta de inveja; apoio; ajuda". Em resumo: "lefarguen" é não só "não ter inveja de alguém", mas também apreciar que alguém possua ou tenha feito algo de extraordinário, merecedor de grande apreciação e que, se não temos simpatia pela pessoa em questão, nós a invejaríamos. Assim, a mencionada forma "inveja boa", dá conta de parte do recado, mas não do todo. Ainda em relação a esta palavra, o ídiche usa ainda mais uma forma dela que não penetrou no hebraico. É uma forma reflexiva, "farguinen zich", significando "permitir-se, dar-se ao luxo de". Quanto a "inveja" mesmo, aquela de corroer a alma, o hebraico tem uma mesma forma para "inveja" e para "ciúme". Freud certamente explica por que "kin'á" abrange os dois sentidos.

Outro tipo de dificuldade com que se defronta quem vai traduzir do hebraico provém de um aspecto que pode soar inusitado: um certo puritanismo que encontrava, até não muito tempo, apoio na tendência de purismo e da norma culta que predominou desde a retomada do hebraico como língua falada e língua da literatura que se propunha a ser base do pensamento de reconstrução espiritual e psicológica do povo judeu após séculos de dispersão, principalmente em oposição ao ídiche, língua popular, das massas. É óbvio que, no dia-a-dia, um vocabulário até chulo, das mais variadas origens, também faz parte do hebraico contemporâneo. A dificuldade se dá quando se vai procurar este tipo de palavras no dicionário. Eis o exemplo: Há pouco, uma editora israelense lançou uma série de romances ditos "eróticos" de autoria feminina. A crítica que os comentou na imprensa dizia que os tais romances sequer a conseguiam "leharmen". Achei que havia entendido a intenção e fui confirmar no dicionário. $\mathrm{O}$ vocábulo não constava como verbo, só como substantivo masculino. O substantivo "harman", para o dicionário de Even Shoshan, edição de 1997, indica que a origem é árabe, e significa "pessoa com instintos sexuais exagerados". Um dicionário mais moderno, como o de Bahat e Mishor, também fica com o substantivo informando que "é alguém que costuma se atirar às 
mulheres com intenções de sexo". O dicionário Sapphire lista como "pessoa tomada de desejos". O Léxico de Gíria Hebraica e Militar, por sua vez, menciona "pessoa que põe as mãos facilmente"- mão boba. O Babylon eletrônico conduz a "voluptuoso"; não podemos, por fim, dispensar o Rav Milon, para o qual "harman" é alguém que "acaricia e toca com desejo sexual"- bolinador. Na edição que acabou de sair do tradicional dicionário de Even-Shoshan, em seis volumes e 2.200 páginas e que, pela primeira vez abre as suas folhas liberalmente para gírias e expressões populares, palavras deste tipo poderão ser encontradas. Segundo a crítica, porém, ainda não foi desta vez que a língua hebraica dicionarizada abrangeu tudo o que poderia e deveria incluir e resolver. Ao tradutor, neste caso, cabe atuar como censor, segundo seus próprios princípios éticos na escolha que fará dentre as diversas opções. Não poderá deixar de levar em consideração que será a partir de sua resolução que o leitor fará o juízo de valor.

Por fim, não podemos deixar de lado a globalização e seus efeitos para os tradutores. Para o caso do hebraico, não se trata apenas de conhecer o inglês e, a partir disto, procurar um significado semelhante no hebraico que conduzirá sem maiores delongas a uma equivalência em português.

Antes de tudo, é importante distinguir dois períodos distintos em que o inglês influenciou o hebraico: no início do século XX, com o substrato britânico devido ao Mandato Britânico na Palestina, e a influência do final do século XX, o substrato norte-americano, pelo fato do inglês norte-americano ser a língua global e a grande vinculação cultural e de outros campos com os Estados Unidos.

A americanização de Israel de hoje é clara na refonologização distintiva de internacionalismos de Israel. Enquanto a refonologização foi originalmente baseada no iídiche, no polonês e no russo, agora ela mostra todos os sinais de americanização. Alguns dos processos são reciclagem de itens léxicos obsoletos, camuflagem de influências estrangeiras, facilitação do aprendizado inicial por via mnemônica. Algumas vezes, uma forma de internacionalização de um vocábulo pré-existente é até suplantada por uma forma americana. Dois pequenos exemplos, e isto vale quando se traduz para o hebraico: antes dizia-se "respekt" (respeito); hoje se usa a pronúncia norte-americana e a respectiva grafia para indicar esta leitura: "rispekt". Outro caso curioso é o que se refere ao nome da jovem moeda européia, o "euro". A Academia de Língua Hebraica, quando do surgimento da moeda, estudou o seu nome que, na grafia européia, é igual à brasileira; a pronúncia na Europa depende de cada país. Do mesmo modo como cada língua pronuncia o nome do continente, Europa, assim pronuncia o nome da moeda. Assim, alemães pronunciam de forma diferente à dos italianos 
ou dos ingleses. A decisão da Academia israelense obedeceu ao mesmo critério. Como em hebraico se diz "Eiropa", a versão hebraica do nome ficou sendo "eiro", grafada de modo compatível. Mas, nos últimos tempos, isto já vem sendo preterido passando à pronúncia com base no inglês: a moeda passou a ser chamada de "yúro".

Para um último exemplo da americanização, e nem de longe pretendo abranger os diversos casos como os de calques, empréstimo camuflado, equiparação fonosemântica, casos em que a equivalência semântica deixa muito a desejar, e assim por diante, valho-me de um modelo apresentado por Zuckermann. Trata-se do sufixo não dicionarizado "ation" (em inglês), o nosso sufixo "ação", que vem entrando com força no lugar da forma hebraica tradicional de substantivação "átsia", que tem exatamente o mesmo sentido. O exemplo está montado a partir de um termo coloquial hebraico no original, "magniv", da raiz g-n-v do verbo "roubar", que, na construção verbal de hif'il, significa "passar ou transferir secreta, furtivamente". Em algum momento, este verbo, na forma do presente, "magniv", na função de adjetivo ou atributo, passou a ser usado como um coloquialismo, significando maravilha, jóia, legal, o máximo, de primeira classe, emocionante. Agora o mesmo "magniv" vem sendo substantivado com o sufixo inglês "ation". O neologismo americanizado é "magnivation", tornar ou tornar-se legal, emocionante. Lembrando que as raízes hebraicas são quase sempre compostas de três consoantes, para se decodificar uma palavra como esta, é preciso um bom jogo de cintura. E, ainda, continuando, temos "magnivizent" (com V), para cuja tradução eu ousaria utilizar formas muito arrojadas como "chocante" ou "animal", segundo um linguajar jovem. É uma construção que se baseou no inglês "magnificent" (com a letra F).

A mobilidade das palavras não respeita fronteiras. Assim, o estudo dos modos e da dinâmica do contato lingüístico e político é vital também para o tradutor que, acima de tudo, deve estar culturalmente bem informado para se defrontar com tudo aquilo que o dicionário não consegue resolver. Deveria cumprir o que o dito ídiche sugere: "A kluguer farshteit fun ein vort tsvei” (Quem é esperto, de uma palavra entende duas). O difícil é saber qual é conveniente.

\section{BIBLIOGRAFIA}

BEN-CALEV, David. "Megged on Megged". The Jerusalem Post, 4/1/2004.

GLAZER, Miriyam. "Resenhas". Hebrew Studies 43, 2002.

GURI, Yossef. Lomir hern gutte b 'soiros: Yiddishe brokhos un klallos. Jerusalém, Hebrew University Press, 2004. 
ROSENTHAL, Ruvik. Hedvat halashon: Sihot al haivrit haisraelit. Tel Aviv, Am Oved, 2004.

SHAKED, Guershon. "Sipur catuv heitev hofech et hadim'a baayin lesim'ha balev". Haaretz, $10 / 5 / 2004$.

ZUCKERMANN, Ghil'ad. "Language Contact and Globalization: The Camouflaged Influence of English on the World's Languages - with Special Attention to Israeli (sic) and Mandarin”. Cambridge Review of International Affairs. Vol. 16, n² 2, julho de 2003.

\title{
DICIONÁRIOS
}

ACHIASAF, O et al. Leksikon hasleng haivri vehatsvai. Tel Aviv, Prolog, 1993.

Milon du-leshoni shimushi ivri-portuguesi portuguesi-ivr Rosh Haayin, Prolog, 2004. AVNEYON, Eitan. The Concise Sapphire Dictionary. Tel Aviv, Hed Arzi \& Eitav, 1997.

BAHAT, Shoshana \& MISHOR, Mordechai. Milon hahove - Milon shimushi laivrit hatiknit. Tel Aviv, Maariv - Eitav, 1995.

BEREZIN, Rifka. Milon ivri-portuguesi. S. Paulo, Edusp, 1995.

CHOUEKA, Y. Rav Milim - Hamilon hashalem. Tel Aviv, Center of Educational Technology, 1997.

EVEN-SHOSHAN, A Hamilon hehadash - hamahadura hameshulevet. Tel Aviv, Kyriat Sefer, 1997.

HARCAVI, Aleksander. Yiddish English Hebreischer Verterbuch. Nova York, Yivo Institute for Jewish Research. 1988.

\begin{abstract}
The large number of factors that intervene in translation from Hebrew is broader than in most contemporary languages. Over and above the historical layers that constitute the language, the profusion and diversity of cultural components pertaining now to the colloquial Hebrew point to the translator's difficulty in fulfilling his/her purpose when relying only on dictionaries. Through examples some of these components are pointed out.
\end{abstract}

Key words: Hebrew language; translation; translation and culture.

90 Nancy Rozenchan - Tradução e o contexto cultural: será que o dicionário basta? 